\title{
ESTÁGIO SUPERVISIONADO NO CURSO DE PEDAGOGIA: NARRATIVAS DE DOCENTES EM FORMAÇÃO
}

\author{
Helena Amaral da Fontoura \\ Universidade do Estado do Rio de Janeiro (UERJ), Rio de Janeiro, Rio \\ de Janeiro, Brasil
}

\begin{abstract}
RESUMO: O presente artigo tem como objetivo analisar as contribuições do estágio supervisionado para alunos do curso de Pedagogia. A pesquisa, de cunho qualitativo, utilizou narrativas (auto) biográficas de 32 discentes de uma instituição pública no estado do Rio de Janeiro, Brasil. A proposta da narrativa escrita foi considerada pelas docentes do componente curricular como uma forma de avaliação mais adequada aos propósitos reflexivos do estágio supervisionado, intervindo diretamente no processo de formação docente para cada licenciando. Utilizamos as contribuições de Tardif, Nóvoa e Pimenta, autores que pensam docência e estágio como elementos da formação de professores. As análises através da tematização conduziram para uma reflexão das vivências em estágio na formação e futura práxis pedagógicas. A investigação possibilitou uma compreensão mais ampla da escola e da universidade como espaços importantes no desenvolvimento profissional docente.
\end{abstract}

Palavras-chave: Estágio Supervisionado. Pesquisa qualitativa. Tematização. Narrativas (auto) biográficas.

\section{INTRODUÇÃO}

O presente artigo tem como objetivo pensar sobre o que dizem alunos e alunas do curso de Pedagogia de uma universidade pública do Rio de Janeiro a respeito das contribuições do estágio supervisionado para sua formação. Temos como preocupação da pesquisa trazer a importância da relação entre universidade e escola básica, ambas instâncias formativas quando tratamos de pensar a docência como processo sempre em construção reflexiva e desenvolvida por todos os espaços envolvidos.

No que se refere à formação profissional para a docência em uma perspectiva reflexiva, consideramos o seguinte aspecto fundante de nossa investigação: o de construir pontes entre a universidade e a escola básica colocadas em diálogo. Nesta pesquisa, incluímos a intervenção, análise e problematizações, buscando caminhos alternativos para um fazer institucional em uma escola de todos e para todos. $O$ espaço do estágio supervisionado é um campo fecundo na construção das identidades profissionais dos licenciandos, e é com esta crença que propomos esta reflexão.

Desde meados da década de 90, Candau (1987) já apontava para a necessidade de se pensar licenciaturas que articulassem conhecimentos específicos e pedagógicos, 
buscando superar fragmentações, pensar os processos de produção e de transmissão de conhecimentos, valorizar a práxis, promovendo articulação teoria e prática desde o início do curso. A autora enfatiza ainda a importância do acompanhamento e da supervisão permanentes nos estágios, a preocupação com o desenvolvimento de práticas interdisciplinares, a busca pela autonomia pedagógica e a preocupação com o desenvolvimento de uma identidade profissional docente.

Nessa perspectiva, nossa pergunta de partida foi: como alunas e alunos de Pedagogia narram a experiência de estágio supervisionado? Com isso, visamos, principalmente, à descoberta de suas expectativas e avaliações sobre o processo vivenciado. Para nosso estudo, o estágio supervisionado sugere um paradigma no qual os saberes da profissão são construídos no percurso de superação de dicotomias, especialmente no que se refere à teoria e prática como componentes distintos da formação. Desenvolvemos uma pesquisa de cunho qualitativo, trabalhando "falas" na perspectiva da narrativa (auto) biográfica, na qual o importante é o que trazem os sujeitos da pesquisa, da forma como trazem, na medida em que a vivência é relatada como percebida.

\section{SOBRE ESTÁGIO SUPERVISIONADO}

A parceria entre universidade e escola, instituída pela Resolução no 9 de 1969 (BRASIL, 1969), dando especial ênfase ao papel do estágio na formação docente, vem se constituindo tema de debates no campo educacional, buscando explicitar dilemas e possibilidades de uma formação que supere dicotomias, que alie teoria-prática-teoria, que resulte em melhores condições de trabalho para professores e de ensinoaprendizagem para docentes e discentes.

O estágio supervisionado no debate sobre processos formativos docentes sugere um paradigma no qual os saberes da profissão são construídos pelos estagiários no percurso de superação de dicotomias, especialmente a que se refere à teoria e prática como componentes distintos da formação. Ao discutirmos questões oriundas da vivência nas escolas, os licenciandos analisam e (re) formulam saberes relativos ao que aprenderam no curso de Pedagogia à luz do que vivenciam nas escolas campo, sem separações entre os momentos de aprendizagem. Isso se torna possível na medida em que temos espaços de discussão sobre textos e temas diversos, em uma visão integradora entre o vivido e o estudado como partes de um todo formativo. A escola campo de estágio é também local de ressignificação de conhecimentos e crenças, de experiências e reflexões sobre os desafios postos a quem decide ser professor, conviver com alunos e alunas produtores de conhecimentos próprios.

Com Certeau (1974), entendemos que as práticas cotidianas são desenvolvidas através de modos circunstancialmente definidos, 'maneiras de fazer', 'procedimentos', que podem ser entendidos se falados, significados no contexto da vida cotidiana, considerados em seus aspectos conscientes e inconscientes. Para Certeau, "o saber-fazer das práticas cotidianas não seria conhecido senão pelo intérprete que o esclarece no seu espelho discursivo, mas que não o possui tampouco"(CERTEAU, 1974, p. 143), ou seja, o autor associa o 'saber fazer' a um 'saber não sabido', um saber sobre o qual os sujeitos não 
refletem. Para ele, "a narrativização das práticas seria uma 'maneira de fazer' textual, com seus procedimentos e táticas próprias" (CERTEAU, 1974, p. 152). O autor nos fala de reinvenção do cotidiano, dizendo que existem mil maneiras de jogar e de desfazer o jogo do outro, no sentido de ser um espaço instituído por outro, e fazer seu próprio caminho, o 'fazer com', desembaraçando-se de uma rede de procedimentos já existentes.

Na perspectiva de não separar a teoria da prática, concordamos com Pimenta e Lima (2010) que apontam o estágio como reflexão da práxis, possibilitando aos estagiários um espaço de aprendizagem com os que já têm alguma experiência docente. Ou seja, a relação com os professores colaboradores que recebem esses estagiários naquele espaço que se apresenta como facilitador de reflexões conjuntas sobre o que fazem e como fazem sua docência, em um processo de produção e significação de seus conhecimentos e saberes. Apontamos ainda que aprender uma profissão tem um aspecto prático, mas também outros processos complementares de observação e avaliação de procedimentos, que vão levar o futuro professor às escolhas que serão feitas na sala de aula quando ingressarem efetivamente na carreira. Assim, os licenciandos vão construindo modelos, fortalecendo o que é bom para eles, sinalizando o que não é, enfim, construindo um ethos profissional, ao mesmo tempo individual e também coletivo, na medida em que o estar na escola proporciona uma troca com professores colaboradores, outros licenciandos e as professoras da universidade.

Contamos também com a contribuição de Alarcão (1996), para quem o estágio deve ser considerado tão importante como os outros conteúdos curriculares do curso. Ou seja, nem um espaço apenas direcionado a 'colocar na prática a teoria aprendida na universidade', nem um componente cursado ao fim do processo apenas para fechar a licenciatura, quase como um apêndice do curso, desvinculado do cerne do processo formativo para a docência. A autora defende uma formação permanente no local de trabalho, apontando a escola como lugar importante para refletir sobre processos de ensino e aprendizagem, já que é na escola que a realidade se apresenta em toda a sua complexidade, onde se evidenciam as tensões entre pensamento e ação, entre as tomadas de decisões e avaliação de seus efeitos. $O$ espaço escolar traz a possibilidade de superar o individualismo ao possibilitar construir conhecimentos por meio da prática coletiva. (ALARCÃO, 2011)

Zeichner (2010) discute algumas questões centrais para os cursos de formação de professores, apontando para uma ausência de conexão entre o que é visto nas universidades e o que acontece efetivamente nas escolas. Fala de sua experiência como formador trazendo o que ele chama de espaços híbridos, nos quais os diversos conhecimentos se juntariam sem hierarquia, para fins de realização de práticas formativas com base em um paradigma mais democrático e inclusivo. Buscar desenvolver espaços com essa finalidade é um de nossos anseios na universidade em que nos inserimos.

Se a universidade oferece aos licenciandos espaços de estágio supervisionado articulados à escola básica nos moldes que defendemos, uma escola colaborativa, refletida, integradora de pensamento e ação, temos bons caminhos para apostar em uma formação referenciada em princípios solidários e cooperativos. Em geral, percebemos, pela nossa experiência, que os processos formativos no estágio supervisionado algumas vezes se prendem a situações estratificadas, discursos que enfatizam as falhas, os fracassos, os modelos a serem copiados ou negados, como também a práticas de professores anteriores que marcaram as vidas dos licenciandos, de forma positiva ou 
negativa. Assim, o estágio é permeado pelas subjetividades, pelas vivências anteriores dos participantes enquanto alunos ou mesmo alguns já como professores, ampliando sua formação em nível universitário.

Vemos que os envolvidos pensam os significados de ser professor a partir das experiências vividas e discutidas, e nossos trabalhos como formadores podem priorizar a construção da autonomia por parte dos licenciandos. No espaço do estágio, os alunos em processo de formação revelam potências e receios. Se o espaço formativo for receptivo às falas diversas, as angústias podem ser relativizadas, dando lugar a soluções criativas e construtoras de uma educação melhor, mais sintonizada com as necessidades de nosso tempo e de nossos sujeitos.

\section{SOBRE NARRATIVA (AUTO) BIOGRÁFICA}

Em relação à abordagem teórico-metodológica (auto) biográfica, no Brasil, o estudo com as narrativas vem sendo utilizado como percurso formativo docente e na pesquisa desde a década de 90. Para Nóvoa (2010), histórias de vida e método (auto) biográfico se integram, reforçando a posição de que ninguém forma o outro, mas sim a visão de formação como reflexiva e reorganizadora dos percursos dos que se formam. Seguindo a mesma perspectiva, Ferrarotti (2014) relata a importância do conhecimento tecido junto com o outro, pois, para ele, "só sabemos junto com os outros" (FERRARROTTI, 2014 , p. 19). Assim, o ser humano não é um dado que pode ser conhecido a partir de um olhar exterior e/ou objetivo, somos "processos em devir, seres ancorados no espaço e no tempo, sujeitos instáveis e incertos". (FERRARROTTI, 2014, p. 19). As narrativas docentes buscam pensar a formação permeada pelo processo reflexivo das histórias de vida que dialogam com a individualidade do professor e com o coletivo.

Daniel Suárez (2008) utiliza a documentação narrativa das práticas docentes como proposta teórica e metodológica que visa a potencializar o saber cotidiano dos professores, tirando o foco dos especialistas da educação, iluminando o saber tecido pelos docentes que estão no chão da escola. $O$ autor ressalta a importância do registro narrativo como documento que precisa se tornar público, assumindo, assim, um ideal políticopedagógico. $\mathrm{O}$ autor, ao valorizar o professor, assume um ideal político. Assim como Nóvoa (2013), ele defende uma reforma escolar que comece dentro da escola, pois, para ambos os pesquisadores, é necessário respeitar as especificidades de cada uma. Ou seja, o trabalho com as narrativas permite uma ressignificação da prática educativa docente e contribui para uma transformação democrática da escola envolvida no processo de troca com a universidade.

Acompanhando o entendimento de Pineau e Le-Grand (2012), o curso de formação docente está marcado por experiências singulares e, pelas narrativas, confere acesso à historicidade, à construção pessoal de sentido. Nas práticas de estágio supervisionado, o futuro que esse presente abre como horizonte de expectativas, capacidades de projeção e também ponte de construção, desenha trajetórias na escola, permitindo ainda mais a exploração dos cenários futuros. Os autores denominam esse processo de 'tomada de existência', quando o sujeito se aproxima da tomada de consciência e da compreensão das aprendizagens. 
A interpretação do conhecimento como construção social da realidade sugere que o licenciando se torne, ele próprio, projeto e autor de projetos (de vida e educativos), que "vão se construindo, reconstruindo, com saber, arte e engenho" (VIEIRA, 2011, p. 84), transversalizando e revelando cenas comuns e experienciais do cotidiano escolar afirmando a singularidade dos processos de aprendizagem e formação.

\section{A PESQUISA: APORTE METODOLÓGICO}

Esta pesquisa qualitativa busca conhecer em profundidade os processos, especialmente os relacionados às práticas, ao universo de significações, valores e atitudes inerentes ao fazer da docência. Reafirmamos que nossa pergunta foi: como alunas e alunos de Pedagogia percebem a experiência de estágio supervisionado? Quais são suas expectativas e avaliações dos processos vivenciados? Com essas questões norteadoras, partimos do pressuposto de que o estágio não se reduz a observação e operacionalização de atividades didáticas, mas, pelo contrário, amplia o espaço que inclui essas dimensões e oportuniza a investigação de sua prática.

Coletamos os dados nas escolas parceiras de um projeto financiado pela Fundação Carlos Chagas de Amparo à Pesquisa do Estado do Rio de Janeiro (FAPERJ). Os 32 licenciandos se encontravam nos últimos períodos do curso de Pedagogia - são participantes da pesquisa e do estágio supervisionado -, eles escreveram as narrativas (auto) biográficas em duas etapas. A primeira foi uma escrita narrativa livre, propostas pelas docentes, buscando as expectativas do estágio supervisionado, e a outra escrita ocorreu após o estágio.

A proposta da narrativa escrita foi considerada pelas docentes do componente curricular como uma forma de avaliação mais adequada aos propósitos reflexivos do estágio supervisionado, intervindo diretamente no processo de formação e apropriação docente para cada licenciando. Todos os participantes fizeram suas narrativas por escrito em sala de aula na universidade, em um mesmo momento, e após a entrega dos registros houve um tempo de troca de relatos que se revelou muito rico.

A análise das narrativas foi feita com a Tematização (FONTOURA, 2011), técnica que possibilita elencar os temas mais relevantes encontrados nos depoimentos. Para a autora, a tematização não é a única maneira de analisar dados na pesquisa qualitativa que são coletados através das entrevistas, dos questionários com perguntas abertas ou dos depoimentos orais. Todavia, com grande experiência na pesquisa etnográfica, ela expõe ao leitor alguns passos da análise, reconhecendo a complexidade (MORIN, 2000) deste processo.

A autora reflete sobre o método de tematização de Paulo Freire na alfabetização de adultos, em que criticava radicalmente a cartilha e a educação bancária. Paulo Freire parte da premissa de que nós somos seres curiosos, inacabados, inconclusos e, portanto, precisamos do outro. Ontologicamente, na perspectiva freireana, precisamos do outro e é com o outro que aprendemos e ensinamos, pois "ensinar inexiste sem aprender e viceversa e foi aprendendo socialmente que, historicamente, mulheres e homens descobriram que era possível ensinar" (FREIRE, 1996, p.13). Freire aponta para uma prática pautada no diálogo, respeito e criticidade visando uma ação transformadora, que valoriza os saberes cotidianos dos povos ordinários, sendo assim, o saber primeiro. $O$ método de Paulo Freire consiste em três etapas: investigação, tematização e problematização. A 
autora defende a ideia de que tanto a alfabetização de adultos, método freireano, quanto à "alfabetização de pesquisadores", são delineados pelos processos de "codificação, aprendizagem e construção de conhecimento que, ao final, produzem cidadania e educação" (p. 63).

Fontoura (2011) sugere alguns passos para organizar os dados coletados. O primeiro consiste na transcrição do material recolhido, como entrevistas gravadas, filmagens, relatos escritos; é aconselhável que o/a pesquisador/a faça a transcrição. $O$ segundo passo demanda uma leitura atenta do material transcrito. Essa etapa é iniciada por uma leitura flutuante, em seguida uma leitura em profundidade com o intuito de ter uma ideia do todo. Depois, na terceira etapa, o pesquisador/a deverá demarcar o corpus da análise, explorar o material, agregar ideias comuns, sem mudar o que trazem os participantes. A quarta etapa consiste em levantar os temas seguindo os princípios da coerência, pertinência ao referencial teórico, objetivo do estudo, exaustividade, ou seja, quando encontramos nas transcrições exemplos de um mesmo tema atingindo assim um esgotamento e por último a exclusividade. A quinta etapa busca definir as unidades de contexto (trechos mais longos) e as de significado (expressões ou palavras).

A análise temática consiste em descobrir os núcleos de sentido que compõem a comunicação e cuja frequência de aparição (desde muito frequente até apenas uma vez) pode significar alguma coisa para o objetivo analítico escolhido. Nessa etapa, o pesquisador/a deve perceber nas falas dos sujeitos da pesquisa os temas emergidos e qual a sua relação com o objeto de estudo. Podemos nos indagar sobre a importância qualitativa dos temas para o objeto de estudo: o tema é fundamental para compreender o objeto de estudo? O tema revela alguma faceta do objeto de estudo que interessa ao pesquisador/a? O tema desvela alguma dimensão do referencial teórico adotado? Nesse momento, novas dimensões teóricas podem surgir, ampliando assim o olhar do pesquisador/a.

Na sexta etapa, é necessário esclarecer a forma de tratar os dados, o que pode ser feito através da elaboração de quadros com unidades de contexto, unidade de significado e comentários. O último passo é marcado pela interpretação de acordo com o referencial teórico adotado. Percebemos que o pesquisador/a implicado/a neste processo deve optar por qual caminho seguir, ancorado/a pelas leituras prévias, mas ciente de que novos horizontes poderão emergir. A análise dos dados é intencional a partir do olhar do pesquisador/a acrescido da visão teórica, mas na medida em que novas perspectivas são ampliadas, os caminhos e as interpretações também o são. Por fim, Fontoura (2011) propõe a análise dos dados em pesquisas qualitativas guiadas na tematização, pautada em uma reflexividade criteriosa dos depoimentos, na qual o pesquisador/a assume o papel de colaborar com os sentidos emergidos na pesquisa, delimita o corpus da análise, levanta unidades contextuais, temas e assume o papel de interpretar os dados.

\section{NARRATIVAS DOS LICENCIANDOS}

Na proposta de escrita deste texto relatando a pesquisa, optamos por não trazer as transcrições na íntegra por considerar que o material cru é fonte de elaboração das 
pesquisadoras. Assim, elegemos para este trabalho a análise dos dois momentos de escrita, já com a tematização apresentando os temas emergentes.

As escritas aconteceram no transcorrer do semestre letivo; na narrativa de escrita inicial o tema emergente mais significativo foi a vontade de conhecer a escola como docente, perspectiva distinta de ser aluno/a anteriormente. As falas trazem curiosidade e ansiedade pelo que está por vir, como: "quero muito ver o que a escola é hoje, fico ansiosa", "vou ver como os alunos lidam com as matérias e como se comportam na escola", "estou com muita vontade de começar logo", e também questões relativas à escolha profissional como, por exemplo, "quero ver se dou mesmo pra professora" e "agora é que vou saber se sigo a carreira".

Ainda na escrita inicial também apareceu, embora com menos intensidade, a ideia de procurar fazer diferente do que foi vivenciado nas experiências enquanto alunos/as anteriormente, dando a entender que não guardavam marcas positivas ou agradáveis de ser aluna/o, o que nas conversas durante o estágio se evidenciaram. Alguns extratos selecionados foram: "quando eu era aluna sofri muito, não quero ser uma professora ruim", "tive uma professora que me marcou por ser muito rígida e grosseira, eu vou fazer diferente" e, ainda, "espero encontrar professores diferentes dos que tive quando era aluna".

Nas narrativas construídas após o estágio supervisionado concluído, as perspectivas se mostraram muito mais confiantes nas possibilidades da profissão docente. Na linha da tematização, encontramos características de um bom professor, como: "para ser professor tenho que ter muita paciência", "só é professor quem ama o que faz", "vi que tenho que estudar muito, um bom professor tem que estar sempre atualizado", ou ainda "ser um professor competente é estudar sempre e refletir sobre o que fazemos".

Um segundo tema fala do estágio supervisionado e sua importância na formação docente, como: "achei a experiência de imersão na escola gratificante", "nunca pensei que fosse aprender tanto com o estágio", "cada dia que eu ia pra escola fazer estágio eu me animava mais", ou mesmo "fazer o estágio reafirmou minha vocação para a docência".

Alguns problemas foram elencados pelos participantes, como "dificuldades de se comunicar com alguns alunos", não aceitação dos estagiários por parte dos professores regentes, "parecia que ela não me queria na sala", trazendo um sentimento de invasão do espaço de sala de aula pertencente a outro professor; também trouxeram situações como, por exemplo, "não saberia explicar o vai um na aula de matemática", ou "coletivos? nunca soube", evidenciando um não conhecimento de conteúdos observados nas salas de aula e não saber como passar o conteúdo para os alunos. Sobre a relação universidade e escola básica, alguns licenciandos trouxeram a importância de desenvolver o estágio articulado e refletido, com a presença das docentes do componente curricular junto na escola todos os dias, com as trocas entre as professoras da escola, participação em conselho de classe, em encontros pedagógicos com a supervisora, e em festas comemorativas de datas do calendário escolar.

As dificuldades observadas foram pontos de discussão nos encontros na universidade, possibilitando que licenciandos fizessem avaliações sobre seus percursos como alunos, os diversos impasses que viveram em suas histórias de vida escolar e como seriam professores diferentes dos que causavam situações de impasse e fracasso escolar 
tão presentes nos depoimentos após a finalização do estágio supervisionado. Além desses momentos de reflexão, buscamos pensar com os licenciandos modos de superar as situações do cotidiano para encontrar caminhos e possibilidades de soluções. A etapa inicial de identificação de impasses pode dar lugar a propostas de atuação que sejam produtivas e prazerosas para os envolvidos.

Alguns licenciandos sinalizaram que algumas professoras colaboradoras aconselhavam que eles saíssem da profissão e fossem fazer outra coisa, afirmando que "não tem futuro aqui", "está cada vez pior", ou sinalizando para baixos salários, alunos sem interesse e condições de trabalho que deixam a desejar. Sousa Neto (2005) aponta que a identidade negativa e a postura de desidentificação com a profissão enfraquecem e comprometem o exercício profissional e as reivindicações, já que defendemos aquilo em que acreditamos e com que nos identificamos positivamente. $O$ autor lembra que baixos salários não são exclusivos apenas do magistério, o que não nega a realidade, mas relativiza o argumento, apontando para as lutas coletivas de melhoria de condições de trabalho e remuneração.

Para Lüdke e Boing (2004), há uma evidência da precarização da profissão docente, uma grande perda de prestígio, de poder aquisitivo, mas o que chama a atenção mesmo é a questão social da insatisfação com a profissão. Também constatam uma nostalgia que valoriza o que já passou, como as falas que trazem o quanto era boa a escola do passado, 'minha escola', ou sobre uma professora marcante, 'minha professora', enfatizando aspectos individuais como determinantes das vivências saudosas atuais. Em um processo de compartilhamento dessas percepções, cria-se a possibilidade de ressignificar essa nostalgia para algo que existe sim, mas que pode ter outra dimensão no coletivo.

\section{ALGUMAS CONSIDERAÇÕES}

Temos clareza dos desafios postos aos que se aventuram a formar professores em uma sociedade desigual como a nossa, trabalhando em universidades públicas muitas vezes em condições longe das desejáveis. Talvez nosso maior desafio seja o que apontamos como entrave na formação de docentes iniciantes (AMARAL DA FONTOURA, 2018), qual seja a permanência na carreira. Enfrentar e superar desafios tem sido a história de formadores de docentes e de docentes nas escolas e universidades. Pesquisas podem auxiliar na compreensão de questões e na superação de impasses gerados na vida profissional cotidiana dos que educam e estudam sobre educar e se educar.

Algumas conclusões foram possíveis a partir da investigação aqui apresentada. Uma delas diz respeito à pesquisa qualitativa e sua importância para compreender o universo educacional, os processos formativos de licenciandos quando em estágio supervisionado, suas expectativas, o que falam sobre o que aprendem e refletem e o papel da universidade como instância formadora. A pesquisa no âmbito da educação permite apreender transições, mudanças e apropriações, neste caso, do saber e da formação dos acadêmicos, reiterando a pertinência das escolhas metodológicas.

As discussões em sala na universidade, a participação das professoras colaboradoras e a escrita (auto) biográfica foram potentes e favoreceram o conhecimento, 
por parte dos licenciandos, da escola real. Puderam se colocar como agentes da docência, ouvir os colegas, relatar situações desafiantes e souberem que é possível encarar os desafios da docência com o que a universidade produz e com o que a escola produz, em uma associação de espaços de construção de conhecimentos.

Ao abrir um leque com as questões sobre o cotidiano escolar e suas reflexões, os licenciandos realizaram articulações pedagógicas possíveis, aprenderam a profissão docente e encontraram elementos de sua identidade na interação e intervenção que conferiram reconhecimento de sua presença naquele espaço. Dessa forma, tornando-se sempre sujeitos de novas experiências, o que Ihes possibilitou refletir sobre a escola enquanto espaço do fenômeno educativo e sobre sua inserção nesse espaço.

Nossa identidade profissional se constrói pelo significado que atribuímos às atividades docentes com base em nossos saberes, nossos valores, nossa forma de lidar no mundo, nossas histórias de vida, nossas experiências, com as dúvidas e angústias que acarretam e com os sucessos e prazeres que trazem. Aprender a profissão docente especificamente no decorrer do estágio supervisionado supõe estarmos atentos às particularidades e às interfaces da realidade escolar em sua contextualização na sociedade. Assim, o estágio supervisionado articulando universidade e escola básica proporcionou, através das narrativas docentes, uma experiência importante e significativa, de avanços e recuos, de significação da escolha profissional para os participantes, que se encontrando em situação real de salas de aula puderam ter um melhor embasamento para pensar os desafios da carreira docente, talvez até mais segurança para o 'constituir-se' professor/a.

Artigo recebido em: 28/01/2019

Aprovado para publicação em: 27/05/2019

\section{SUPERVISED PRACTICUM IN PEDAGOGY COURSE: NARRATIVES BY TEACHERS TO BE}

ABSTRACT: This article aims to analyze the contributions of the supervised internship to students of the Pedagogy course. The qualitative research used (self) biographical narratives of 32 students from a public institution in the state of Rio de Janeiro, Brazil. The proposal of the written narrative was considered by the teachers to be more adequate form of evaluation to the reflexive purposes of the supervised practice, thus intervening directly in the process of teacher training and appropriation for each teacher to be. We use the contributions of Tardif, Nóvoa and Pimenta, authors who think about teaching and internship as elements of teacher training. The analysis through thematization led to a reflection of the experiences at the training stage and future pedagogical praxis. Research has enabled a broader understanding of schools and University as important spaces in teacher professional development.

KEYWORDS: Supervised practicum. Qualitative research. Thematization. (Auto) biographical narratives.

PRÁCTICAS SUPERVISADAS EN EL CURSO DE PEDAGOGÍA: NARRATIVAS DE DOCENTES EN FORMACIÓN 
RESUMEN: Este artículo tiene como objetivo analizar las aportaciones de las prácticas supervisadas a los alumnos del curso de Pedagogía. La investigación, de carácter cualitativo, utilizó narrativas (auto)biográficas de 32 estudiantes de una institución pública en el estado de Río de Janeiro, Brasil. La propuesta de la narrativa escrita fue considerada por docentes del componente curricular como una forma de evaluación más adecuada a los propósitos reflexivos de las prácticas supervisadas y por lo tanto intervenir directamente en el proceso de formación y la asignación de la enseñanza para cada licenciando. Utilizamos las aportaciones de Tardif, Nóvoa y Pimenta, autores que piensan en la enseñanza y la práctica como elementos de la educación docente. El análisis a través de la tematización condujo a un reflejo de las experiencias en la pasantía en la formación y futura praxis pedagógica. La investigación permitió una comprensión más amplia de escuela y universidad como espacios importantes en el desarrollo profesional de los docentes.

PALABRAS CLAVE: Prácticas supervisadas. Investigación cualitativa. Tematización. Narrativas (auto) biográficas.

\section{REFERÊNCIAS}

ALARCÃO, I. Formação reflexiva de professores - estratégias de supervisão. Porto, Porto Editora, 1996.

ALARCÃO, I. Entrevista - Formação docente e escola reflexiva. 2011. Disponível em : https://gestaoescolar.org.br/conteudo/490/isabel-alarcao-fala-sobre-formacao-docentee-a-escola-reflexiva. Acesso em 08 de junho de 2017.

AMARAL DA FONTOURA, H. Narratives by initial teachers. Education \& Self Development. v.13, p.10 - 18, 2018.

ARGILATA, M.T.A. La investigación cualitativa. Educar, Curitiba, n. 10, p. 23-50, 1986.

BRASIL. Conselho Federal de Educação. Resolução nº 9, de 6 de outubro de 1969.

CANDAU, V. L. (Coord). Novos rumos da licenciatura. Brasília, INEP, Rio de Janeiro, Pontifícia Universidade Católica do Rio de Janeiro, 1987.

CERTEAU, M. A invenção do cotidiano. São Paulo, Cortez, 1974.

DENZIN, N. K. The research act. a theoretical introduction to sociological methods. New York, McGraw-Hill, 1970.

FERRARROTTI, Franco. História e história de vida. Trad. Carlos Eduardo Galvão e Maria da Conceição Passeggi. Natal, RN, EDUFRN, 2014. 
FONTOURA, H. A. da

FONTOURA, Helena Amaral da. Analisando dados qualitativos através da tematização. In: FONTOURA, Helena Amaral da (Org). Formação de professores e diversidades culturais: múltiplos olhares em pesquisa. 1. ed., Niterói, Intertexto, 2011, p.61-82.

FREIRE, Paulo. Pedagogia da Autonomia: saberes necessários à prática educativa. São Paulo, Paz e Terra, 1996.

LUDKE, M.; BOING, L. A. Caminhos da profissão e da profissionalidade docente. Educação e Sociedade. Campinas, v. 25, n. 89, p. 1159-1180, 2004.

MORIN, Edgar. Os setes saberes necessários à educação do futuro. 2. ed. São Paulo, Cortez, Brasília, DF, UNESCO, 2000.

NÓVOA, Antonio. Nada substitui um bom professor: propostas para uma revolução no campo da formação de professores. In: GATTI, Bernardete Angelina [et al.] Por uma política nacional de formação de professores. 1. ed. São Paulo: UNESP, 2013.

PIMENTA, Selma G. O estágio na formação de professores: unidade, teoria e prática? São Paulo, Cortez, 1997.

PIMENTA, Selma G.; LIMA, Maria S.L. (Orgs.) Estágio e docência. São Paulo, Cortez, 2010.

PINEAU, Gaston; LE GRAND, Jean-Louis. As histórias de vida. Trad. Carlos Eduardo Galvão Braga e Maria da Conceição Passeggi. Natal: EDUFRN, 2012.

SOUSA NETO, M. F. O oficio, a oficina e a profissão: reflexões sobre o lugar social do professor. Cadernos Cedes, Campinas, v. 25, n. 66, p. 249-259, maio/ago. 2005.

Disponível em: http://www.cedes.unicamp.br. Acesso em: 27 mai. 2011.

SUÁREZ, Daniel H. La documentación narrativa de experiencias pedagógicas. La indagación-acción del mundo escolar para la reconstrucción de la memoria pedagógica de lós docentes. In: VII Seminário Redestrado- Novas Regulaciones em América Latina, 3, 4 e 5 de Julio de 2008, Buenos Aires. Anais. Disponível em: http://www.fae.ufmg.br/estrado/cdrom_seminario_2008/textos/ponencias/Ponencia\%2 0Daniel\%20Su\%C3\%A1 rez.pdf. Acesso em: 05 jan. 2016.

TARDIF, M. Saberes docentes e formação profissional. Petrópolis, Vozes, 2002.

VIEIRA, R. Educação e diversidade cultural: notas de Antropologia da Educação. Porto, Afrontamento, 2011.

ZEICHNER, K. M. Repensando as conexões entre a formação na universidade e as experiências de campo na formação de professores em faculdades e universidades. Revista Educação, Santa Maria, v. 35, n. 3, p. 479-504, set-dez, 2010. 
Helena Amaral de Fontoura: Professora Titular Faculdade de Formação de Professores da Universidade do Estado do Rio de Janeiro.

Orcid: https://orcid.org/0000-0003-2795-8246

E-mail: helenafontoura@smail.com

Este periódico utiliza a licença Creative Commons Attribution 3.0, para periódicos de acesso aberto (Open Archives Iniciative - OAI). 